\title{
Investigation on Factors Affecting Small and Micro Enterprise Performance: in the Case of South Wollo zone, Ethiopia
}

\author{
Melkamu Temesgen Tariku (MA) Getachew Gesesse Asfaw (MBA) \\ Abdurohman Awol Adem(MBA) Denekew Gebiru Gebrehiwot (MBA) \\ Department of Management, Mekdela Amba University, Wollo, Ethiopia
}

\begin{abstract}
The study area of this research is delimited to South Wollo Zone. The main objective of the study is to investigate factors affecting small and micro enterprise performance which are found in south Wollo Zone. The specific objectives of the study are designed from management factors, public infrastructure, marketing factors, government and legal support and access to finance perspective. The research design for this is explanatory, while the approach is mixed approach. It is also cross sectional research design based on the time of contact. The target populations for the study are employees who are engaged small and micro enterprise of the target zone. Both probability and non-probability sampling techniques are used and $\mathbf{3 6 3}$ samples were selected based on Yamane (1967) formula. Primary data was used to fulfill the research objective. In order to analyze the data SPSS version 20 was used. A multiple regression model was used to show cause and effect between the study variables. The study findings reveal that the major determinant tools for micro and small enterprises performance were public infrastructure, management factors and access to finance. Because these variables have positive and significant effect on micro and small enterprises performance, however among the study variables marketing factors and government and legal support have positive but insignificant effect on the micro and small enterprises. The study finds that small and micro enterprises of South Wollo zone are faced with serious problems such as lack of managerial skill, public infrastructure problem, access to finance problems and marketing problems.
\end{abstract}

Keywords: management factors, public infrastructure, access to finance, small and micro enterprise performance, and South Wollo zone.

DOI: $10.7176 / \mathrm{EJBM} / 12-22-02$

Publication date:August $31^{\text {st }} 2020$

\section{Introduction}

\subsection{Background of the Study}

Nowadays SMEs are becoming increasingly important in terms of employment, wealth creation, and the development of innovation. The importance of the SME sector is well recognized worldwide due to its significant contribution to gratifying various socio-economic objectives, such as higher growth of employment, output, promotion of exports and fostering entrepreneurship. Gurmeet \& Rakesh (2008), and Deksiso( 2018), states that SMEs are seen as the main actors of both national and regional development in many countries. Micro and smallscale enterprises are important both to the individual and to the nation. They contribute more enormously to the socioeconomic development of once country.

Even though small and micro enterprises contribute to the development of the nation, they are affected by many factors. Varieties of factors are identified by researchers which affect micro and small enterprise performance. Most factors that identified by researchers and find in literature are infrastructure, finance, managerial skill, training, age sex, family size and location.

\subsection{Problem statement}

Most fast developing countries MSE by virtue of their size, location, capital investment and their capacity to contribute for poverty reduction and generate greater employment have proved their powerful effect for rapid economic growth. According to (Ngima,2014), the informal sector is increasingly viewed as an important engine for employment creation and economic growth.

Many researches are conducted regarding factors affecting micro and small scale enterprise performance. However they don't reach consensus on the factors listed by these researchers and the effect of these variables on small and micro enterprise performance. Researchers such as, find that business management skills, record keeping, financial access, infrastructure facilities and training have significant effect on small and micro enterprise performance. On the other hand the research finding of ; conclude that access to finance, managerial skills, age sex, access to business information did not significantly affect performance of SMEs.

Emmanuel \& Ndebugri (2018) revealed that most reviews in developing nations show that SMEs have problems related to lack of managerial skill, public infrastructure, and access to finance. Since 2001, micro and small enterprises (MSEs) in Ethiopia have been confronted with several factors that affect their performance. Major factors include financial problems, lack of qualified employees, lack of proper financial records, marketing problems and lack of work premises, etc . 
Even though the above researchers identify various factors that affect small and micro enterprise performance, none of them conduct their researches by combining the effect of management factors, infrastructure, marketing factors, government and legal issues, and access to finance on small and micro enterprise performance. The other gap is these researchers' (researchers listed above), conceive micro and small enterprise performance solely as single variable, but in our view small and micro enterprise performance is broad and general term that should be viewed with various parameters to manifest it. Furthermore, we couldn't find on factors that affect small and micro enterprise performance of south Wollo Zone. In line with these gaps the researchers develop the following research objectives.

\subsection{Research objective}

1.3.1. Main research objective

The main objective of this research is to investigate factors affecting small and micro enterprise performance: in the case of South Wollo zone

1.3.2. Specific research objectives

1. To examine how management factors affect small and micro enterprise's performance.

2. To investigate how public infrastructures affects small and micro enterprise's performance.

3. To analyze to what extent access to finance affects small and micro enterprise's performance.

4. To examine how government and legal issues affect small and micro enterprises performance.

5. To investigate how marketing factors affect small and micro enterprise's performance.

\subsection{Scope of the study}

This research is limited to South Wollo selected woredas regarding factors affecting small and micro enterprise performance. The study area for this research is confined to Legambo woreda , Mekaneselam city administration and Kelala woreda. In this research, factors such as managerial skills, infrastructure, market access, government and legal support and access to finance. Small and micro enterprise performance in this research context includes profitability and employment. The target populations in this study were owners and employees who are engaged in small and micro enterprise in Legambo, Mekaneselam and Kelala.

\section{Review of Related Literature}

Ethiopia has a long tradition in the development of handcrafts and cottage manufacturing activities such as weaving, blacksmithing, pottery, and woodwork. But the introduction of modern industries began at the end of the 19th century, (Mulatu, 2005). In Ethiopia, public policy concerns for the development of small enterprises extend as far back as the Axumite Empire around the first century A.D. Even though Ethiopia has a long tradition in the development of handicrafts and cottage manufacturing SME s were not developed very well. Mulatu (2005), postulates that even the recent well known three Ethiopian emperors Theodros II (1855-1867), Yohannes IV (1870-1887), Haileselassie(1935-197) and the Derg regime(1974-1991), failed to promote Small and micro enterprises. It was since 1991, the Government of the Federal Democratic Republic of Ethiopia has recognized the promotion and development of small enterprises as important vehicles in addressing the challenges of unemployment, economic growth and equity.

\subsection{Factors Affecting Small and Micro Enterprise Performance}

I. Management Factors: Simply, managerial skills are the knowledge and ability of the individuals in a managerial position to fulfill some specific management activities or tasks. This knowledge and ability can be learned and practiced (Williams ,2009). Many SMEs owners or managers lack managerial training and experience. The typical owner or managers of small businesses develop their own approach to management, through a process of trial and error. Most SME owners as result, their management style are likely to be more intuitive than analytical, more concerned with day-to-day operations than long-term issues, and more opportunistic than strategic in its concept .

II. Access to finance: According to (Beck, Asli, \& Honohan, 2008), financial access is critical for the growth of small and micro enterprises (SMEs). IFS (2011), states that access to finance allows entrepreneurs to innovate, improve efficiency, expand to new markets, and provide millions of jobs. Yet, in developing countries, the majority of SMEs are unable to acquire the financing they need to reach their potential. However Financing SMEs in the developing world can be risky and expensive for lenders.

III. Public infrastructures: The literature presented by (Torrisi, 2009), indicates infrastructure facilities are important features related to economic performance. Access to public infrastructure comprise, water, electricity, serviceable roads, telecommunication, telephones, electronic media and postal services which are all crucial for business startup, development and growth. Limited access to public infrastructure services is a major constraint to SMEs performance (Babajide,2016).

IV. Marketing factors: the research finding of (Bembenutty, White, \& Vélez 2016) and Antenane, (2017), 
discussed, inadequate market and difficulty in searching new market, lack of demand forecasting, and asymmetry in market information, poor customer relationship and, lack of promotion to attract potential customers are marketing constraints.

V. Government support and legal issues: SMEs require a favorable institutional framework. SMEs often miss out on tax incentives or business subsidies. They suffer more than big companies from the large burden and cost of bureaucracy. Micro and small enterprises face difficulties at every stage of their activities, whether it is buying materials for production, organization of production, selling products in the market or sustaining the period between production and marketing.

\subsection{Performance Measurement in small and Microenterprise}

According to ,the MSE operations worldwide plays a pivotal role by adding value to the economy by creating jobs, enhancing income, lowering costs and adding business convenience. Profitability is important for the survival of the SMEs. Without it, the continuation of a firm is doubtful. The word profitability is composed of two words, namely, profit and ability. The term profit is a measure of receipts less cost and the term ability indicates the power of a business entity to earn profits. The ability of a concern also denotes its earning power or operating performance. Therefore, profitability may be defined as the ability of a given investment to earn a return from its use. The profitability of micro and small enterprises highly depends on the financial decisions that are made by the owners ranging from financing to working capital management and saving decisions

2.3. Conceptual framework of the study: The developed conceptual framework for this study portrays the relationship between independent variables (access to finance, management factors, infrastructure, marketing factors and government support and legal issues) and a dependent variable (SME performance) from the perspective of SME performance and profitability employment creation.

\section{Independent variables}

dependent variable

* Access to finance
- Management factors
- Mnfrastructure
- Governeting factors
issues

\section{SME performance}

$\rightarrow$ Profitability

$\rightarrow$ Employment creation

Figure 2.1: Conceptual framework (developed based on empirical review)

\section{Research Methodology}

Explanatory research design and mixed approach was adopted to achieve the objectives of the study. Furthermore based on the time of contact the research design for this research is cross sectional research design. The targeted populations for this study were 3832 employees and owners of small and micro enterprise who are engaged small and micro enterprise activities. Both probability and non-probability sampling techniques were used. Small and micro enterprises were purposively selected on the basis of the researcher's university mandate area and their proximity. With regard to probability sampling the researchers used simple random sampling with stratification. The base of stratification is department (enterprise category). The formula of Yamane 1967 was used in order to select the sample from the target population.

$$
\mathbf{n}=\frac{\mathbf{N}}{\mathbf{1}+\mathbf{N}} \text { Where: } \mathrm{N}=\text { population, } \mathrm{n}=\text { sample size, } \mathrm{e}=\text { margin of error }(5 \%)
$$

$\mathrm{n}=3832 / 1+3832 * 0.05 * 0.05=\mathbf{3 6 3}$

The population was divided into five strata's (enterprises category) and then the samples were proportionally allocated as shown in the following table.

Table .1: sample size

\begin{tabular}{|l|l|l|}
\hline Departments(enterprises category) & Population & Selected sample \\
\hline Manufacturing & 605 & $605 / 3832 * 360=57$ \\
\hline Urban agriculture & 297 & $297 / 3832 * 360=28$ \\
\hline Service & 1162 & $1162 / 3832 * 360=110$ \\
\hline Trade & 1396 & $1396 / 3832 * 360=132$ \\
\hline Construction & 372 & $372 / 3832 * 360=35$ \\
\hline Total & 3832 & 363 \\
\hline
\end{tabular}

Regarding data collection methods; primary data, both open ended and close ended questionnaires were used.

Data was analyzed by using descriptive statistics, correlation and regression with SPSS version 20. Spearman 
correlation was used to show the relationship of variables. Regression model was developed as follows to show cause and effect.

$\mathbf{Y}=a+\beta 1 \times 1+\beta 2 \times 2+\beta 3 \times 3+\beta 4 \times 4+\beta 5 \times 5+£$

$\mathbf{Y}=$ Dependent variable (SME performance)

$\boldsymbol{\beta}=$ coefficient

$\boldsymbol{a}=$ the " $\mathrm{y}$ " intercept, $\mathbf{X} \mathbf{1}=$ public Infrastructure, $\mathbf{X} 2=$ Access to finance, $\mathbf{X} \mathbf{3}=$ management factors, $\mathrm{X} 4=$ marketing factors, $\mathrm{X}, 5=$ government support and legal issues, $£=$ error term

Validity and Reliability: Regarding validity, researchers have elaborated questionnaires to those of respondents by using their mother tongue. After all the researchers were collect, analyzes and interprets data as impartially as possible. In this research Cronbach alpha was used to test reliability. Before distributing all research questionaries' to the selected samples, pilot survey was conducted for 30 employees and owners of small and micro enterprises and the following results were obtained.

Table 2: reliability test of the grand study variables

\begin{tabular}{|l|l|r|rr|}
\hline \multicolumn{2}{|c|}{} & $\mathrm{N}$ & & $\%$ \\
\hline \multirow{3}{*}{ Cases } & Valid & 30 & & 100.0 \\
\cline { 2 - 6 } & Excluded $^{\mathrm{a}}$ & 0 & & .0 \\
\cline { 2 - 5 } & Total & 30 & & 100.0 \\
\hline
\end{tabular}

\section{Reliability Statistics}

\begin{tabular}{|r|rr|}
\hline Cronbach's Alpha & N of Items & \\
\hline
\end{tabular}

As it can be seen from the table the Cronbach alpha value of 6 study variables(Public infrastructures, marketing factors, management factors, access to finance, government and legal support and micro and small enterprises performance) is 0.709 , which means they are reliable.

\section{Data analysis}

At first data's were presented through descriptive statistics followed by the correlation analysis which is used to show the relationship between the study variables. Finally results of multiple linear regressions are presented in order to estimate the value of micro and small enterprises performance from independent variables (factors affecting it).

4.1. Descriptive statistics: The mean statistical value approaching were based on the assumptions of .If the mean value is between ( 1 to 1.5 ) this implies the respondents strongly disagreed, if the mean value is between [1.50 to 2.50 ) it indicates the respondents disagreed, the mean value between [2.50 to 3.50) indicates the respondents were neutral but in this research context medium, the mean value between [3.50 to 4.50) implies the respondents agreed and a mean value 4.50 and above shows the respondents strongly agreed.

Table 3: the grand mean of study variables

\begin{tabular}{|c|l|c|c|r|}
\hline No. & Study variables & N & Mean & Std. Deviation \\
\hline $\mathbf{1 .}$ & Public Infrastructures & 336 & 2.6866 & .98098 \\
\hline $\mathbf{2 .}$ & Marketing Factors & 336 & 2.9048 & .47143 \\
\hline $\mathbf{3 .}$ & Management factors & 336 & 2.8419 & .38070 \\
\hline $\mathbf{4 .}$ & Access to Finance & 336 & 2.9060 & .81956 \\
\hline $\mathbf{5 .}$ & government and legal support & 336 & 2.2705 & .40219 \\
\hline $\mathbf{6 .}$ & Micro and small enterprises performance & 336 & 2.3251 & .71650 \\
\hline
\end{tabular}

Source: own survey (June, 2019)

The Overall score of all independent variables (public infrastructure marketing factors, management factors, access to finance) with the mean value of 2.686, 2.9048, 2.8419 and 2.9060 , which means there is no guarantee that these variables may not available in good manner. The overall score of, government and legal support shows and 2.2705 , which means there is a problem(lack) of government and legal support . The dependent variable (Micro and small enterprises performance) indicates that mean of 2.3251 and standard deviation of 0.71650 , which indicates poor performance of Micro and small enterprises.

The open ended questionaries' survey result also supports the close ended questionaries' result.by open ended questionaries' survey the following results obtained.

I. Marketing problem were lack of market integration, high cost of raw materials, market fluctuation and inflation.

II. Public infrastructure problems were lack of reliable infrastructure, poor road transportation electricity, and water and telecommunication problem.

III. Management problems were regarding the problem of malignancy among the enterprise owners, lack of 
entrepreneurship and capacity building training and they run their enterprises not because they like it rather they don't have any other option to work.

IV. Access to finance problems: these problems are related to high interest charges, excessive bureaucracy to get credit, and little or no financial institutions to borrow funds and lack of record keeping knowledge.

V. Problems regarding to government support and legal issues were excessive bureaucracy to obtain credit, illegal trade and money and products are stolen by thief.

VI. Poor performance of small and micro enterprises: The poor performances of small and micro enterprises are in fact due to the problem of the above problems (access to finance problem, public infrastructure problems, marketing problem, management problem, government and legal support problems).

$\checkmark$ Due to problem of access to finance and transportation problem they failed to deliver products and services to their customers.

$\checkmark$ Due to lack of workspace they failed to enough products to their customers

$\checkmark \quad$ Taxes are not levied accordingly

$\checkmark \quad$ Lack of innovation based support

$\checkmark$ Due to lack of public infrastructure(water, electricity, transportation and telecommunication)

$\checkmark$ Due to lack of market integration they earn low profit

$\checkmark$ Due to the problem of access to finance their enterprises failed to grow and employee more persons.

4.4 Correlation Analysis

Table 5: correlation analysis of the study variables

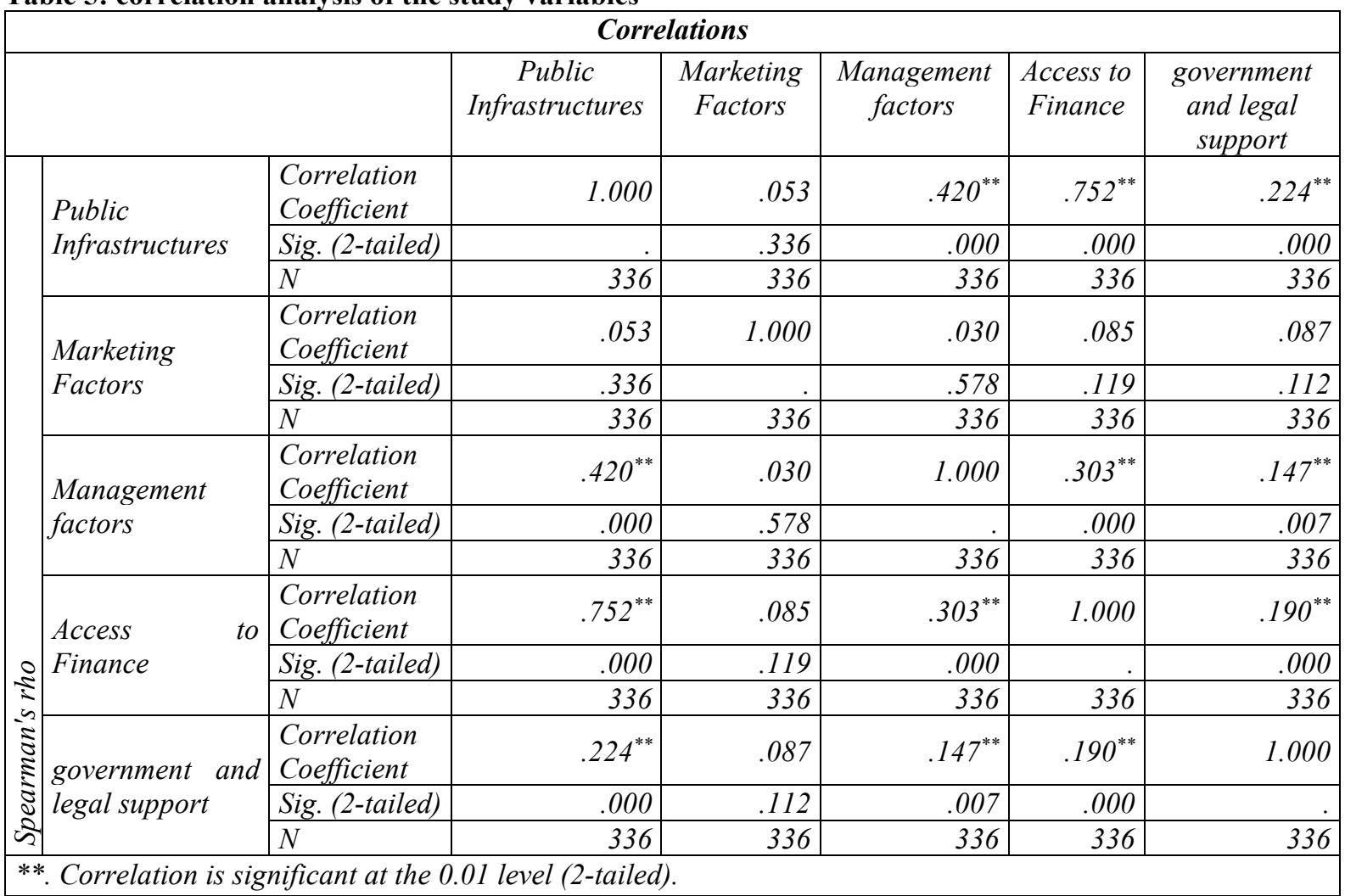

\section{Source: own survey (June, 2019)}

Public Infrastructures have relationship with marketing factors, management factors, and access to finance, government and legal support with the value of $0.053,0.40,0.72$ and 0.224 . Marketing factors have relations with the public infrastructures, management factors, and access to finance, government and legal support with the value of $0.053,0.03,0.085$ and 0.087 . Management factors have relations with marketing factors, public infrastructures, and access to finance, government and legal support with the value of $0.420,0.030,0.303$ and 0.147 . Access to finance, have relations with marketing factors the public infrastructures, management factors and government and legal support with the value of $0.752,0.085,0.303$ and ,0.190. Government and legal support, have relations with marketing factors, public infrastructures, management factors and access to finance with the value of $0.087,0.224$, 0.147 and 0.190 . Generally from the above correlation we can understand that there is strong relationship between access to finance and public infrastructures. There is moderate relationship between management factors and public infrastructures. Similarly there is moderate relationship between management factors and marketing factors. Furthermore there is moderate relationship between access to finance and management factors. All other variables 
have week relationship one another.

4.5. Regression Analysis of Study Variables: This part of study presents outputs analyzed through multiple linear regressions. The outputs included are model summary of the regression, ANOVA statistics and regression coefficients.

\begin{tabular}{|l|r|r|r|r|}
\hline \multicolumn{6}{|l|}{ Table 6: Model Summary } \\
\hline Model & \multicolumn{1}{l|}{ R } & R Square & Adjusted R Square & Std. Error of the Estimate \\
\hline 1 & $.879^{\mathrm{a}}$ & .772 & .769 & .34464 \\
\hline
\end{tabular}

a. Predictors: (Constant), government and legal support, Marketing Factors, Management factors, Access to

Finance, Public Infrastructures

Source: own survey (June, 2019)

$\mathrm{R}$ in this model represents a correlation between the predicted and observed values of the outcome is valued $87.9 \%$. So the correlation shows there is strong relationship between variables. The value of $\mathrm{R}$ square tells that independent variables can account $77.2 \%$ variation in small and micro enterprises performance. Here R Square may be may be overestimate and it is better to look for adjusted $\mathrm{R}$ square. The adjusted $\mathrm{R}$ square tells us that independent variables can predict small and micro enterprises performance by $76.9 \%$. The Standard Error of the Estimate tells us that nearly $34.464 \%$ may be wrongly estimated.

\section{Analysis of variance (ANOVA)}

Table 7: ANOVA table

\begin{tabular}{|l|l|r|r|r|r|r|}
\hline \multicolumn{7}{|c|}{ ANOVA $^{\mathrm{a}}$} \\
\hline \multicolumn{1}{|l|}{ Model } & Sum of Squares & \multicolumn{1}{c|}{ Df } & Mean Square & \multicolumn{1}{c|}{ F } & Sig. \\
\hline \multirow{3}{*}{1} & Regression & 132.782 & 5 & 26.556 & 223.589 & $.000^{\mathrm{b}}$ \\
\cline { 2 - 8 } & Residual & 39.195 & 330 & .119 & & \\
\cline { 2 - 8 } & Total & 171.977 & 335 & & &
\end{tabular}

a. Dependent Variable: Micro and small enterprises performance

b. Predictors: (Constant), government and legal support, Marketing Factors, Management factors, Access to Finance, Public Infrastructures

Source: own survey (June, 2019)

From the ANOVA statistics we can understand that from the total number of observation (171.977), the regression model explains 132.782. The remaining 39.195 is not explained by the model. Here the regression explains most of observation whereas the lesser observations are explained by other extraneous variables. Mean square of the model (regression) represents the average amount of variation explained by the model is 26.556 whereas mean square of the residual is .119 which indicates the average amount of variation explained by extraneous variables (the unsystematic variation). The F-ratio which, is a measure of the ratio of the variation explained by the model and, the variation explained by extraneous variables.

4.6. Coefficients of small and micro enterprise performance Table8: Coefficients of small and micro enterprises performance

\begin{tabular}{|c|c|c|c|c|c|c|}
\hline \multirow{2}{*}{\multicolumn{2}{|c|}{ Model }} & \multicolumn{2}{|c|}{ Unstandardized Coefficients } & \multirow{2}{*}{$\begin{array}{c}\text { Standardized Coefficients } \\
\text { Beta }\end{array}$} & \multirow[t]{2}{*}{$\mathrm{t}$} & \multirow[t]{2}{*}{ Sig. } \\
\hline & & $\mathrm{B}$ & Std. Error & & & \\
\hline \multirow{6}{*}{1} & (Constant) & -.035 & .203 & & -.171 & .864 \\
\hline & Public Infrastructures & .527 & .033 & .721 & 16.108 & .000 \\
\hline & Marketing Factors & .022 & .040 & .015 & .549 & .584 \\
\hline & Management factors & .152 & .056 & .081 & 2.723 & .007 \\
\hline & Access to Finance & .119 & .037 & .136 & 3.229 & .001 \\
\hline & Government and Legal Support & .045 & .049 & .025 & .922 & .357 \\
\hline
\end{tabular}

a. Dependent Variable: Micro and small enterprises performance

\section{Source: own survey (June, 2019)}

From the above table it can be understand that Public infrastructures, management factors and access to finance have positive and significant effect on micro and small enterprise performance at $\mathrm{P}<0.05$. With these three variables the $t$ value is greater than 2 . Government and legal support and marketing factors have positive but insignificant effect on micro enterprise performance. The objective of the regression in this study is to find such an equation that could be used to find the effect of predictors on dependent variable. The specified regression equation was:

$\mathrm{Y}=\mathbf{- 0 . 0 3 5}+\mathbf{0 . 5 2 7}+\mathbf{0 . 0 2 2} \mathrm{X} 2+\mathbf{0 . 1 5 2 X 3}+\mathbf{0 . 1 1 9 X 4}+\mathbf{0 . 0 4 5 X 5}+\mathrm{e}$

Where $\mathrm{Y}=$ Micro and Small Enterprise Performance, X1= Public Infrastructures; X2= Marketing Factors: X3 $=$ Management Factors; X4 = Access to Finance X5= Government and Legal issues: $\mathrm{e}=$ the residual amount.

The regression equation above shows that, by taking all factors into account constant at zero, the micro and 
small enterprise performance will have the value of -0.035 .

And the findings presented also show that taking all other independent variables at zero, a unit increase in public infrastructures will increase micro and small enterprise performance by 0.527 . A unit increase on marketing factors increase will increase micro and small enterprise performance by 0.022 . A unit increase on management factors will increase micro and small enterprise performance by 0.152 . A unit increase on access to finance will increase micro and small enterprise performance by .119. A unit increase on governments and legal support will increase micro and small enterprise performance by 0.045

\section{Summery Concussion and Recommendation 5.1. Summary of Findings}

The objective of this research was mainly to achieve the research questions designed in the statement of the problem. And regarding to the objectives of the study the research finds:

$>$ Public infrastructure highly affects small and micro enterprises performance.

$>$ Management factors have positive and significant effect on small and micro enterprises performance.

$>$ Accesses to finances have positive and significant effect on small and micro enterprises performance.

$>$ Government and legal supports have positive but significant effect on small and micro enterprises performance.

$>$ Marketing factors have positive but significant effect on small and micro enterprises performance.

Conclusion: In this study, the major determinant tools for micro and small enterprises performance were Public infrastructure, Management factors and access to finance. Because these variables have positive and significant effect on micro and small enterprises performance, however among the study variables marketing factors and government and legal support have positive but insignificant effect on the micro and small enterprises. But these factors (independent variables are not performed well) because their mean score shows neutral which results in poor micro and small enterprises performances.

Recommendation: Based on the findings of the study the researcher suggested the following points which need to be implemented starting from the year this research have been conducted. If performed effectively that micro and small enterprises performance will be enhanced. Concerned authorities (transport authority and the communication offices), shall improve public infrastructures. Furthermore technique and vocational enterprises shall provide training and provide support for small and micro enterprises.

Suggestion for future research: The current study was carried out only about factors affecting small and micro enterprise performance in the case of selected woredas in south wollo Zone (Mekaneselam city administration, Kelala and Legambo), The next research shall include other woredas which are found in South Wollo by including other variables such as return on investment, working premises, technological factors, education, age and sex.

\section{References}

Anne, N. (2014, January). Factors Affecting the Performance of Small and Medium Enterprises in the Jua Kali Sector In Nakuru Town, Kenya. IOSR Journal of Business and Management (IOSR-JBM), 80-93.

Antenane, A. E. (2017, June 30). Factors affecting performance of Micro and Small Enterprises in Addis Ababa: $\mathrm{m}$ The case of Addis Ketema Sub City Administration.

Asad, H., Akhtar, M., \& Javaid', M. (2011). Human Resource Practices and Enterprise Performance in Small and Medium Enterprises of Pakistan. First International Conference on Contemporary Issues of Business, (pp. 118).

Babajide, A. (2016, February ). Effects of Microfinance on Micro and Small Enterprises (MSEs) Growth in Nigeria. Asian Economic and Financial Review.

Beck, T., Asli', D., \& Honohan, P. (2008, May 15). Access to Financial Services: Measurement, Impact and Policies. The World Bank Research Observer.

Belay, G. (2000). Evaluation of the performance of the private sector economy in Ethiopia.

Bembenutty, H., White, M., \& Vélez, M. (2016). Developing self-regulation of learning and teaching skills among teacher candidates self-regulated learning and development in teacher preparation training. .

Buchner, A. K., \& Schmidt, D. (2008). infrastructure private equity. center of private equity research, discussion paper. 1-328.

Deksiso, G. G. (2018, June). Assessment of the factors affecting the performance of micro and small scale enterprise: The case of Wolkite town, Guraghe zone, Southern Ethiopia. Journal of Development and Agricultural Economics, 6, 192-199.

Desta, S. (2010). Studies conducted on women entrepreneurs in Ethiopia.

Emmanuel, T., \& Ndebugri, H. (2018, january 19). Examining business performance of micro, small and medium scale enterprise through accounting records keeping; case study in Ghana.

Ghalib, A., Malki, I., \& Imai, K. (2011). The impact of microfinance and its role in easing poverty of ruralhouseholds: Estimations from Pakistan. Research Institute for Economics and Business Administrtion. . 
Gurmeet, S., \& Rakesh, B. (2008). Entrepreneurship and micro and small enterprises in Ethiopia: evaluating the role, prospects and problems faced by women in this emergent sector. An International Journal.

Habtamu, A. ,. (2013). Growth determinants of micro and small enterprise (MSE) micro and small enterprises: evidence from Northern Ethiopia. Journal of Economic and Sustaintainable Development, 128-135.

Heslina. (2016). Factors affecting the business performance of the micro, small and medium enterprises in creative economic sector in Makassar, Indonesia. SCIRJ, 4, 41-49.

Hidayet, K., Canan, g., \& Onur, S. (2010). The Importance of SMEs in Developing Economies. 2nd International Symposium on Sustainable Development. Sarajevo.

IFS. (2013). Access to finance is key to inclusive economic growth in Sub-Saharan Africa. .

Kamunge, M., Njeru, A., \& Tirimba, O. (2014, December ). Factors affecting small and micro enterprise in Limuru town: Market of kiyambu county Kenya. International Journal of Scientific and Research Publications, 4.

Karen, D., \& Jerry, B. (2002). Performance Measures For Microenterprise In The United States.

Katz, J. (2009). Empowering the Workforce, Industry Wee.

Mekonnen, D. (2013). Deterrents to the success of micro and small enterprises in Akaki-Kality Sub-City.

Mesfin, S. (2015). Challenges and Prospects of Small Enterprises in Ethiopia:A Study of Entrepreneurs in Tigray Region.

Mulatu, D. (2005). Small businesses in small towns of the Eastern Tigray Region: Nature and economic performance. Chamber of Commerce.

Ngima, K. (2014). Factors Affecting the Performance of Small and Medium Enterprises in the Jua Kali Sector In Nakuru Town, Kenya. IOSR Journal of Business and Management, 16, 80-93.

Obokoh, L., \& Goldman, G. (2014). Infrastructure deficiency and the performance of small- and medium-sized enterprises in Nigeria's Liberalized Economy. Acta Commercii - Independent Research Journal in the Management Sciences, 1-10.

Olusola, O. (2013). Estimating growth in investment of micro and small scale enterprises in Nigeria . Asian Economic and Financial Review, 111-123.

Robbins, S., \& Coulter, M. (2012). Management (11 ed.). Pearson Education, Inc.,

Robert, B. B., \& Richard, A. B. (2008). Business Research Methods and Statistics. London: SAGE Publications Ltd.

Ruth, W., Karanja, N., \& Gichuhi, W. (2014). effects of managerial skills on the growth of incubated micro and small enterprises in kenya.

International Journal of Social Sciences and Entrepreneurship,

Sánchez, J. (2011). University training for entrepreneurial competencies: Its impact on intention of venture creationl. International Entrepreneurship and Management Journa, 7, 239-254.

Singh, K. (2006). Fundamental of research methodology and statistics. New Age International.

Syed, H. H., Minaa, F., \& Rana, Z. (2017, February 06). Microfinance and Performance of Micro and Small Enterprises; Does Training have an impact. Journal of Entrepreneurship and Business Innovation, 4.

Tomas, C., Muluken, Z., \& Shimelis, T. (2017, July 21). Examining significant factors in micro and small enterprises performance: case study in Amhara region, Ethiopia.

Torrisi, G. (2009, January ). Public infrastructure: definition, classification and measurement issues. 1-35.

Tushabonwe, K. (2006). Causes of Small Business Failure in Uganda: A Case Study from Bushenyi and Mbarara Towns. African Studies Quarterly .

Werotaw, B. (2010). Entrepreneurship: an engine for sustainable growth, development, prosperity and good governance; genius training and consultancy service. Amen Business Group press, Addis Ababa, Ethiopia.

Williams, C. (2009). Management. South-Western, a part of Cengage Learning. 